\title{
Hodgkin's disease of the thoracic vertebrae
}

Masashi Uehara, MD'); Jun Takahashi, MD, PhD 1);

Hiroki Hirabayashi, MD, $\mathrm{PhD}^{1)}$; Jun Kitahara, $\mathrm{MD}^{1)}$; Tetsuyoshi Kamijyo, $\mathrm{MD}^{1}$ );

Sohei Ebara, $\mathrm{MD}, \mathrm{PhD}$ 2); Hiroyuki Kato, $\mathrm{MD}, \mathrm{PhD}^{1)}$

${ }^{1)}$ Department of Orthopaedic Surgery

Shinshu University, School of Medicine

3-1-1 Asahi, Matsumoto City, Nagano 390-8621, Japan

Tel: 81-263-37-2659

Fax: 81-263-35-8844

${ }^{2)}$ Department of Orthopaedic Surgery

Chigasaki Tokushukai Medical Center

14-1 Saiwai-town, Chigasaki City, Kanagawa 253-0052, Japan

Tel: 81-467-85-1122

Fax: 81-467-83-9798 
Correspondence and requests for reprints to:

Jun Takahashi, MD, PhD

Department of Orthopaedic Surgery

Shinshu University, School of Medicine

3-1-1 Asahi, Matsumoto-City, Nagano 390-8621, Japan

Tel: $81-263-37-2659$

Fax: 81-263-35-8844

E-mail: jtaka@ shinshu-u.ac.jp 


\title{
Hodgkin's disease of the thoracic vertebrae
}

\author{
Abstract \\ Background Context: Hodgkin's disease rarely occurs in the spine, which is usually a \\ setting for the advanced form of the disease. \\ Purpose: To describe an unusual case of isolated, primary spinal Hodgkin's disease, and to \\ draw attention to this disease as a possible diagnosis in patients with mixed inflammatory \\ cell infiltrate lesions located in the thoracic spine.
}

Study Design/Setting: A case report of a 28-year-old woman who presented with back pain and progressive weakness in the lower extremities as a result of spinal cord compression due to Hodgkin's disease of the thoracic vertebrae.

Methods: We report a new case of spinal cord compression due to Hodgkin's disease of the thoracic vertebrae. Decompression surgery was performed in the patient, followed by antibiotic treatment.

Results: Antibiotic therapy temporarily improved inflammation and fever. However, magnetic resonance imaging (MRI) evaluation showed that the inflammatory reaction in the lesion was not completely resolved. The disease progressed and later investigations 
revealed Hodgkin's disease, which improved with a course of chemotherapy and radiation.

Conclusions: Hodgkin's disease should be considered in the differential diagnosis of spinal neoplastic lesions with clinical features similar to spondylitis. Since MRI evaluation showed that the vertebral disc was maintained in this case, the presence of a tumor rather than inflammation should have been suspected.

KEY WORDS: Extranodal lymphoma; Hodgkin's disease; Lymphoma; Spinal cord; Spinal cord compression 


\section{INTRODUCTION}

Hodgkin's disease most commonly presents with progressive but painless enlargement of peripheral lymph nodes, especially around the cervical region. Non-Hodgkin's lymphoma arises in the lymph nodes in approximately $60 \%$ of patients and at extranodal sites in approximately $40 \%$ of patients [1]. On the other hand, Hodgkin's disease is believed to arise in the lymph nodes in $90 \%$ of patients, and at other sites in the remaining $10 \%$ of patients. The incidence of Hodgkin's disease with spinal cord compression is rare, and the spine is usually a setting for the advanced form of the disease [2]. An initial manifestation of spinal cord compression due to Hodgkin's disease in the spine is extremely rare. We describe a 28-year-old woman who initially presented with spinal cord compression due to Hodgkin's disease of the thoracic spine.

\section{CASE REPORT}

A 28-year-old woman presented with a history of upper back pain that began after January 2002, 5 months before admission. Her height was $156 \mathrm{~cm}$, and her weight was $45 \mathrm{~kg}$. A month before admission, she began to develop progressive weakness in the lower extremities 
and numbness below the upper thoracic area. Her medical history indicated no abnormalities.

A physical examination on admission revealed remarkable bilateral lower extremity weakness that was worst in the hip flexors but did not preclude walking. A subjective decrease in pinprick sensation below the $4^{\text {th }}$ thoracic dermatome was noted. Increased tone and hyperreflexia in the lower extremities, with bilateral Babinski signs, were also observed. A T2-weighted sagittal magnetic resonance imaging (MRI) scan of the thoracic spine showed a high-signal mass in the region anterior to the $1^{\text {st }}-3^{\text {rd }}$ thoracic vertebra and an epidural lesion (Fig. 1). Extensive soft tissue swelling and enhancement around the lesion, with kyphotic deformity and spinal cord compression, were present. Contrast-enhanced MRI showed that the epidural space and spinous process around the vertebral level from the $1^{\text {st }}-3^{\text {rd }}$ thoracic vertebra were enhanced, but the lesion did not invade the intervertebral disc. Routine blood analysis gave the following results: white blood cell count, $9900 / \mu \mathrm{L}$; C-reactive protein level, $6.24 \mathrm{mg} / \mathrm{dL}$; erythrocyte sedimentation rate, 114/118 mm; soluble interleukin (IL)-2 receptor level, $865 \mathrm{U} / \mathrm{mL}$; and normocytic anemia (red blood cell count, $373 \times 10^{4} / \mu \mathrm{L}$; hemoglobin, $10.4 \mathrm{~g} / \mathrm{dL}$; hematocrit, 32.0\%). In addition, the results of various tests for infection and a tuberculin skin test were negative. Analysis of chest radiographs indicated no abnormalities besides the destructive thoracic spine lesion associated with a soft tissue mass and kyphotic deformity. Computed tomography (CT) demonstrated osteolytic 
change of vertebral bodies, pedicles, and laminas in both the $2^{\text {nd }}$ and $3^{\text {rd }}$ thoracic vertebrae.

In particular, a lesion near the muscle density presenting at the site of the vertebral body

from anterior to lateral in the $2^{\text {nd }}$ thoracic vertebra and tracheal compression were seen.

Gallium-67 scintigraphy showed abnormal accumulation around the $2^{\text {nd }}$ thoracic vertebra.

Considering the above-mentioned diagnostic information, the differential diagnosis included spinal tuberculosis, pyogenic spondylitis, malignant lymphoma, and other neoplastic lesions.

Since the paralysis of both legs became worse and MRI showed an increase in lesion size 3

weeks after admission, we performed posterior decompression from the $1^{\text {st }}-3^{\text {rd }}$ thoracic vertebra, open biopsy, debridement, and drainage. Histological findings from the tissue removed during surgery showed chronic inflammatory infiltrates with necrosis, but no neoplastic cells. Bacterial and fungal cultures were negative. We performed polymerase chain reactions with the tissue, but tuberculosis, Mycobacterium avium, and Mycobacterium intracellulare tests were negative. Acid-fast bacilli were detected (Gaffky 2). Antibiotic treatment with new quinolones and macrolides improved the inflammatory reaction and clinical manifestation, and the spine lesion became smaller. Therefore, we assumed that the lesion was spondylitis due to an atypical mycobacterium, and performed chemotherapy with new quinolones, macrolides, and antituberculous medications. 
However, the inflammation gradually worsened, with a 2- or 3-week cycle of remission and exacerbation. Thus, we concluded that antibiotic treatment could not improve the inflammation and performed a posterior-approach anterior spinal cord decompression from the $1^{\text {st }}-3^{\text {rd }}$ thoracic vertebra, open biopsy, debridement, and drainage 5 months after admission. Histological analysis showed no neoplastic cells. An acid-fast bacterial stain was also negative, and there was only inflammatory infiltration present. Even after surgery, the inflammatory reaction did not improve.

Six months after admission, chest CT showed a large lesion at the anterior mediastinum, and CT-guided needle biopsy was performed at the site (Fig. 2). Histological analysis (hematoxylin-eosin [H.E.] $\times 10$ ) of the biopsy specimen showed inflammatory infiltrates with fibrosis and necrosis (Fig. 3). Reed-Sternberg (RS) cells were seen under a high-power field ( $\times 200)$, as well as lymphoma cells that were immunoreactive for CD15 and CD30 (Fig. 4). At this point, we diagnosed spinal cord compression due to Hodgkin's disease of the thoracic vertebrae. The antibiotic and antituberculous medications were stopped, and the patient was treated with adriamycin, bleomycin, vinblastine, and decarbazine (ABVD) and subjected to radiation therapy of the thoracic spine. The lesion markedly reduced in size. The 
inflammatory reaction and clinical condition were also significantly improved. Due to the reduction in lesion size and clinical improvement observed after 12 cycles of ABVD, we performed posterior fusion from the $5^{\text {th }}$ cervical to the $7^{\text {th }}$ thoracic vertebra 13 months after admission, because we had performed bilateral total facetectomy during posterior-approach anterior spinal cord decompression previously. When we performed posterior-approach anterior spinal cord decompression, we could not use instrumentation because we were wary of infection. The patient's lower extremities showed improved strength and she was able to return to work. MRI at the 6 years after surgery showed no evidence of recurrence (Fig. 5). No further evidence of disease has been noted elsewhere in the patient during 10 years of follow up (Fig. 6).

\section{DISCUSSION}

Hodgkin's disease accounts for $0.5-1 \%$ of all adult neoplastic diseases [3]. In $90 \%$ of patients with Hodgkin's disease, the disease is thought to arise in the lymph nodes, whereas in the remaining $10 \%$ of patients the disease arises at other sites [1]. Spinal lesions occur in $5.8 \%$ of Hodgkin's disease patients [4]. Wood and Coltman estimated that primary 
extranodal presentation of Hodgkin's disease occurs in $<0.25 \%$ of patients [5]. Spinal lesion with extranodal Hodgkin's disease as the primary presentation is even more uncommon.

Spinal cord compression caused by a malignant lymphoma is generally a late manifestation of the disease [6]. There are about 3 times more patients with non-Hodgkin's disease than those with Hodgkin's disease [7]. Between 0.1-6.5\% of patients with non-Hodgkin's lymphoma develop spinal cord compression at some time during the course of their disease, usually because of an epidural tumor mass. Fifty of 1039 patients (5\%) with non-Hodgkin's lymphoma in one series developed central nervous system (CNS) involvement [8]. Four percent had leptomeningeal disease, $1 \%$ had intracerebral lesions, and $0.1 \%$ had spinal cord compression. Only 5 of the 50 patients $(0.5 \%)$ had CNS involvement at the time of initial presentation. In another series, $9 \%$ of patients with non-Hodgkin's lymphoma developed CNS involvement [9]. The sites involved were the leptomeninges (4\%), the spinal epidural space (3.5\%), and within the cerebrum $(1.5 \%)$. Half of the cases of spinal cord compression were found at the time of initial diagnosis. Spinal cord compression occurs much less often in Hodgkin's disease [10-12]. To our knowledge, the case described here is only the ninth case and the third report of a patient with Hodgkin's disease who presented with spinal cord compression due to epidural and spinal disease without lymphoma 
elsewhere [13-15]. Spinal cord compression due to Hodgkin's disease is very rare and usually develops in the setting of a diffuse, undiagnosed disease or at some time after the initial diagnosis.

We encountered some difficulties in determining the diagnosis of Hodgkin's disease in our case. Firstly, there was a high level of inflammatory reaction, fever, and spondylotic features in radiologic and histological findings. Secondly, histological evaluation of the spine lesion did not show RS cells, which are essential characteristics for the diagnosis of Hodgkin's disease. Finally, the inflammatory reaction and fever were temporarily improved by our antibiotic therapy, which possibly resulted from the effect of the drugs on the inflammatory cytokines produced by the tumor. In our case, the vertebral disc was maintained to the end, which we believe to be a feature of Hodgkin's disease of the spine. Thus, Hodgkin's disease should be considered a possible cause of any spondylosis-like lesion without vertebral disc invasion.

This patient represents an unusual case of primary extranodal Hodgkin's disease of the thoracic vertebrae with spinal cord compression. We successfully treated this patient with 
focal field radiation therapy and systemic chemotherapy (ABVD). No further evidence of the disease has been noted elsewhere in the patient during 10 years of follow-up.

\section{CONCLUSION}

We reported an unusual case of primary, isolated Hodgkin's disease of the thoracic vertebrae with spinal cord compression. Focal field radiation therapy and systemic chemotherapy (ABVD) were effective, and showed a good prognosis. The presence of a tumor rather than inflammation should be suspected in cases when MRI confirms that the vertebral disc is maintained. 


\section{References}

[1] Ultmann JE, DeVita VT Jr. Hodgkin's disease and other lymphomas. In: Petersdorf RG, Adams RD, Braunwald E, Isselbacher KJ, Martin JB, Wilson JD, eds. Harrison's principles of internal medicine. 10th edition. New York: McGraw-Hill, 1983:811-25.

[2] Mullins GM, Flynn JP, el-Mahdi AM, et al. Malignant lymphoma of the spinal epidural space. Ann Intern Med 1971;74;416-23.

[3] Van der Wall H, McLaughlin AF, Southee AE. Gallium scintigraphy in tumor diagnosis and management. In: Murry IPC, Ell PJ, eds. Nuclear medicine in clinical diagnosis and treatment, vol. 2. Edinburgh: Churchill Livingstone, 1998:813-29.

[4] Correale J, Monteverde DA, Bueri JA, et al. Peripheral nervous system and spinal cord involvement in lymphoma. Acta Neurol Scand 1991;83;45-51.

[5] Wood NL, Coltman CA. Localized primary extranodal Hodgkin's disease. Ann Intern Med 1973;78;113-8.

[6] Friedman M, Kim TH, Panahon AM. Spinal cord compression in malignant lymphoma. Treatment and results. Cancer 1976;37;1485-91.

[7] Haddad P, Thaell JF, Kiely JM, et al. Lymphoma of the spinal extradural space. Cancer $1976 ; 38 ; 1862-6$. 
[8] Herman TS, Hammond N, Jones SE, et al. Involvement of the central nervous system by non-Hodgkin's lymphoma. Cancer 1979;43;390-7.

[9] Levitt LJ, Dawson DM, Rosenthal DS, Moloney WC. CNS involvement in the non-Hodgkin's lymphomas. Cancer 1980;45;545-52.

[10] Lascalles RG, Burston J. Hodgkin's disease. Arch Neurol 1962;7;359-64.

[11] Sapozink MD, Kaplan HS. Intracranial Hodgkin's disease. Cancer 1983;52;1301-7.

[12] Steinherz PG, Walker R, Kroll G, et al. Lymphomatous leptomeningitis as a presenting syndrome of Hodgkin's disease. Ann Intern Med 1983;99;342-3.

[13] Ginsburg S. Hodgkin's disease with predominant localization in the central nervous system. Arch Intern Med 1927;39;571-95.

[14] Love JG, Miller RH, Kernohan JW. Lymphomas of spinal epidural space. Arch Surg $1954 ; 69 ; 66-76$.

[15] Citow JS, Rini B, Wollmann R, Macdonald RL. Isolated, primary extranodal Hodgkin's disease of the spine: case report. Neurosurgery 2001;49;453-7. 


\section{Figure legends}

Fig. 1: MRI results demonstrated that the region from the $1^{\text {st }}-3^{\text {rd }}$ thoracic vertebral body had been replaced by an osteolytic mass (left). Enhancement around the lesion and spinal cord compression were present (right). However, the lesion did not invade the intervertebral disc.

Fig. 2: Computed tomography at 6 months after admission (right) showed a larger lesion at the anterior mediastinum compared with that at the time of admission (left).

Fig. 3: Histological examination (hematoxylin-eosin [H.E.] $\times 10$ ) of the biopsy specimen showed inflammatory infiltrates with fibrosis and necrosis.

Fig. 4: High-power field (×200) images showing RS cells, and lymphoma cells that were immunoreactive for CD15 and CD30.

Fig. 5. MRI at the 6 years after surgery showed no evidence of recurrence.

Fig. 6. Plain radiographs showed no abnormality 10 years after surgery. 


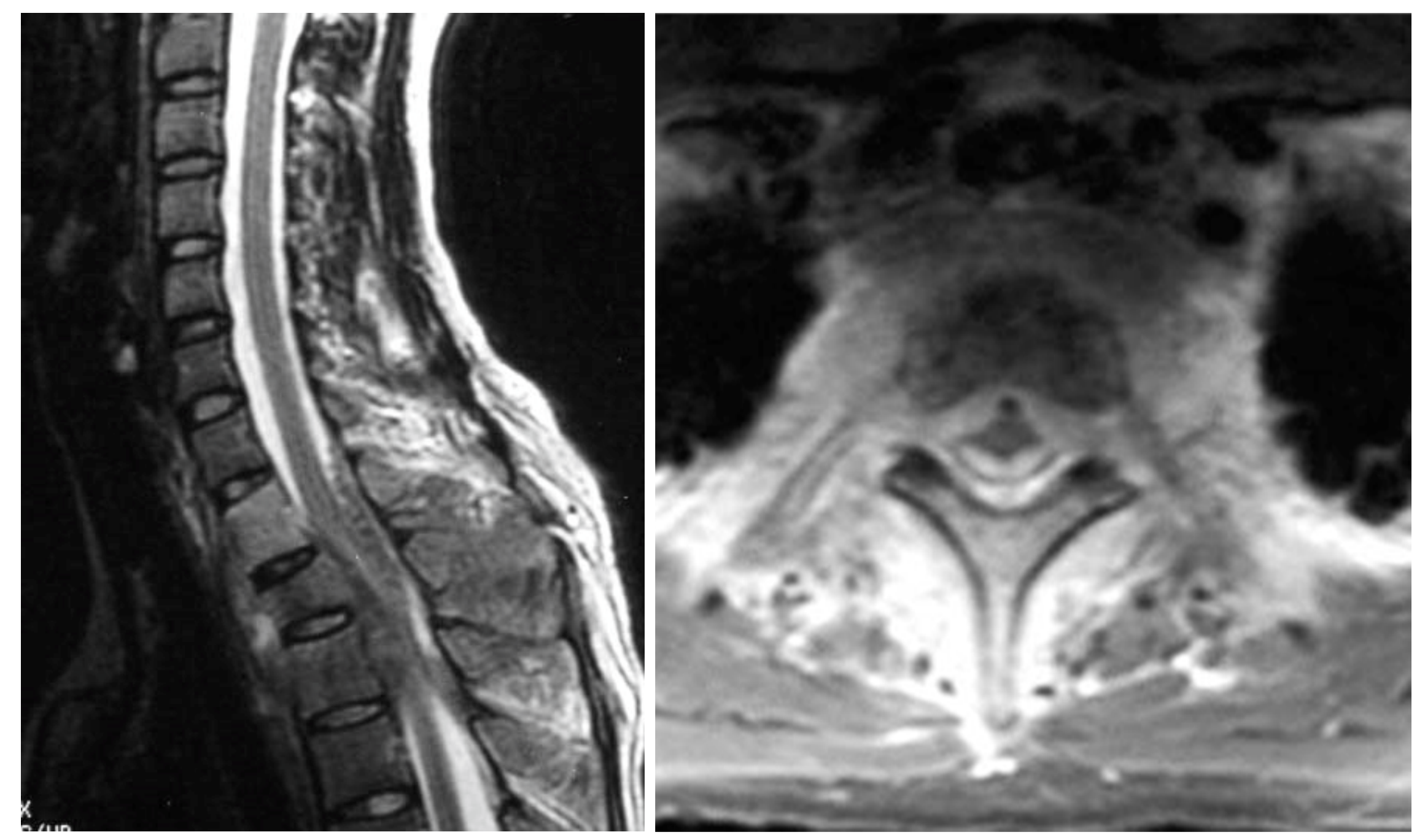

Fig. 1 


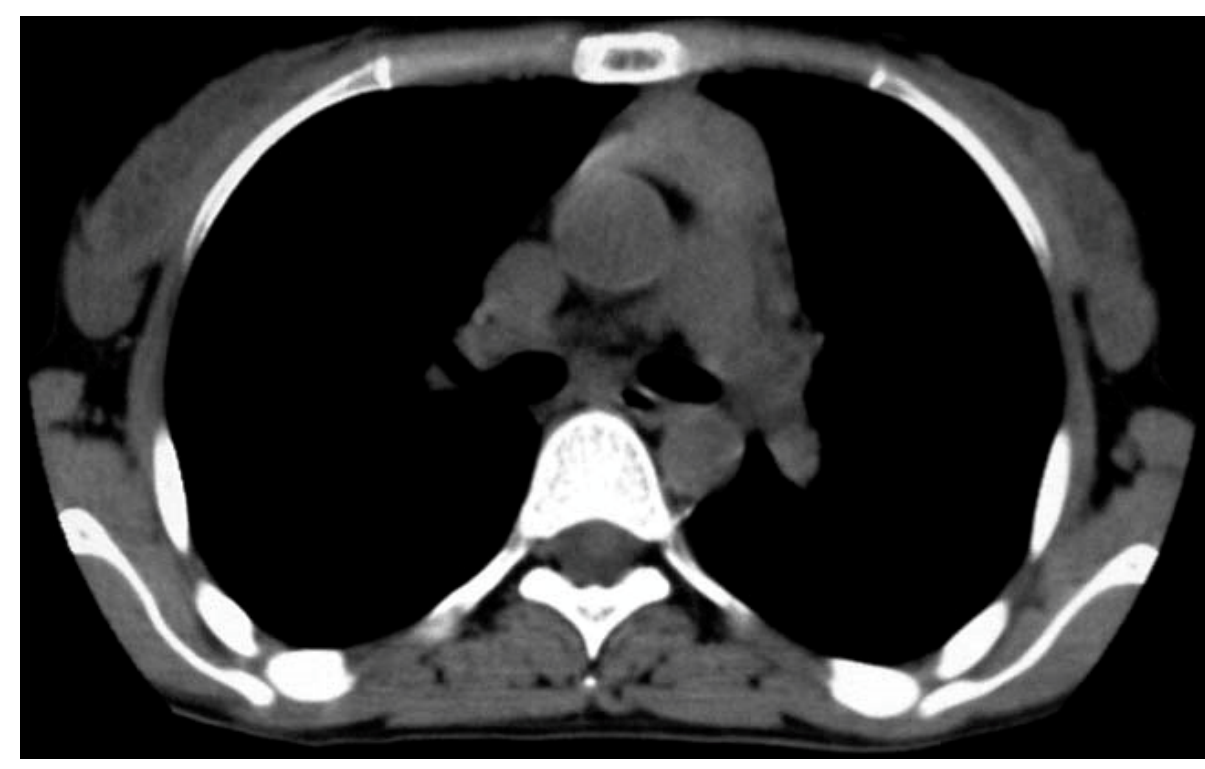

On admission

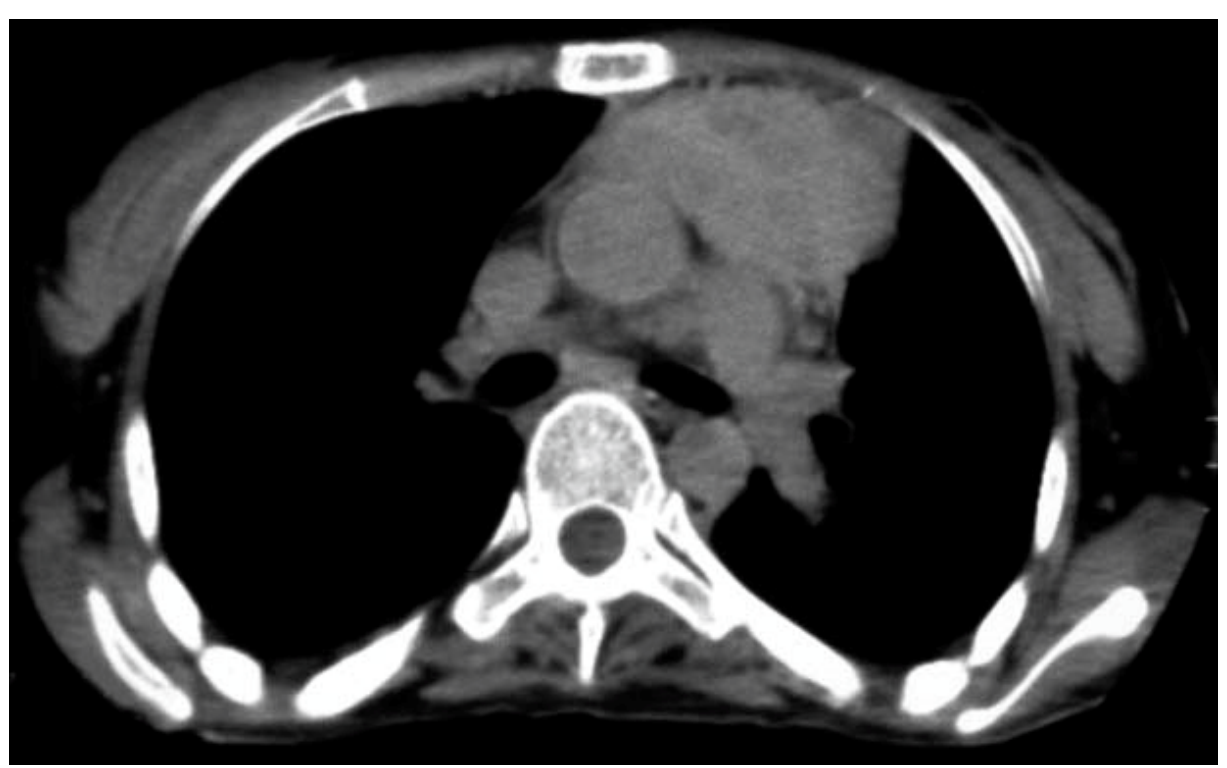

6 months after admission

Fig. 2 


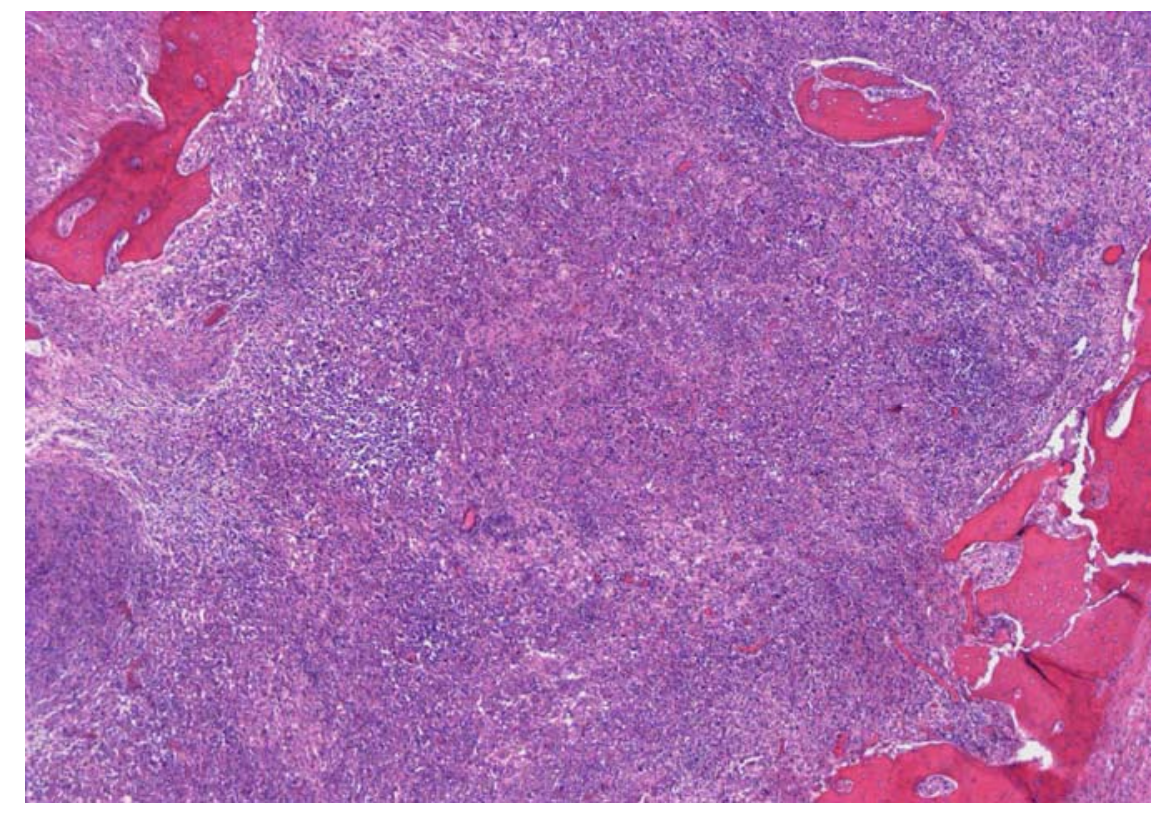

H.E. x10

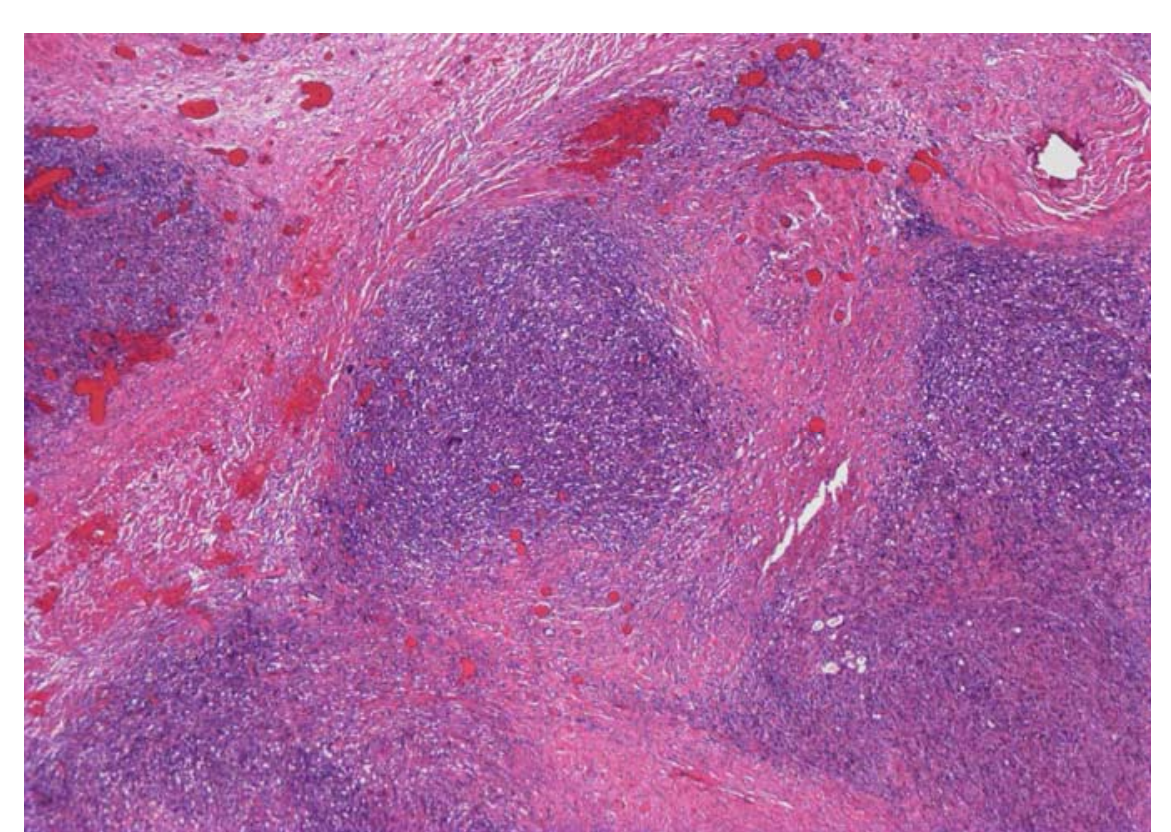

H.E. x10

Fig. 3 


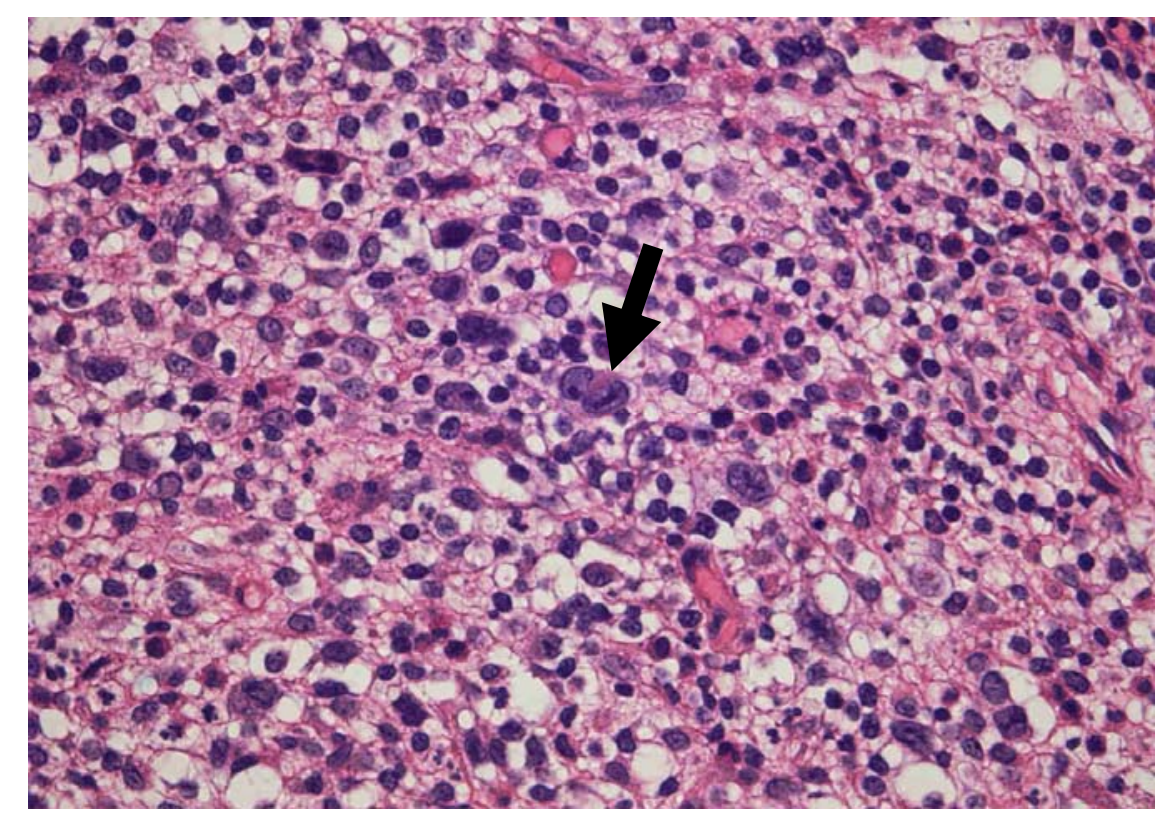

H.E. x100

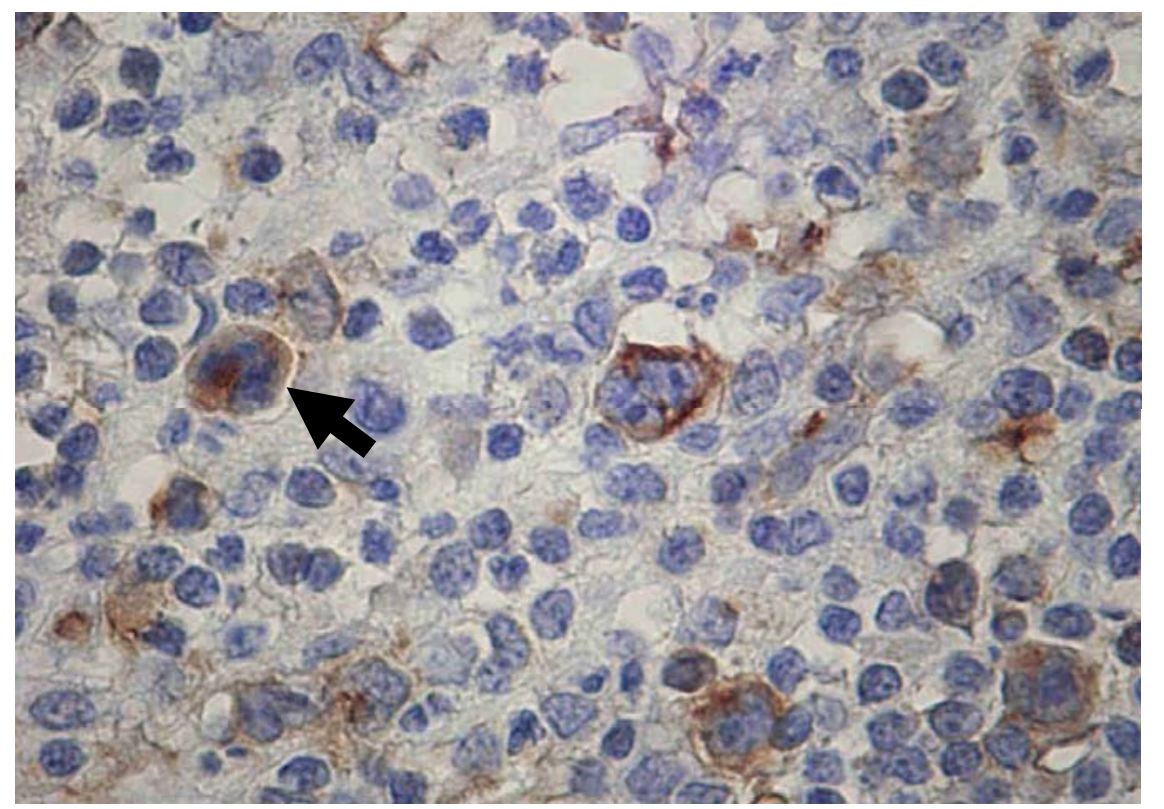

CD30 x200

Fig. 4 


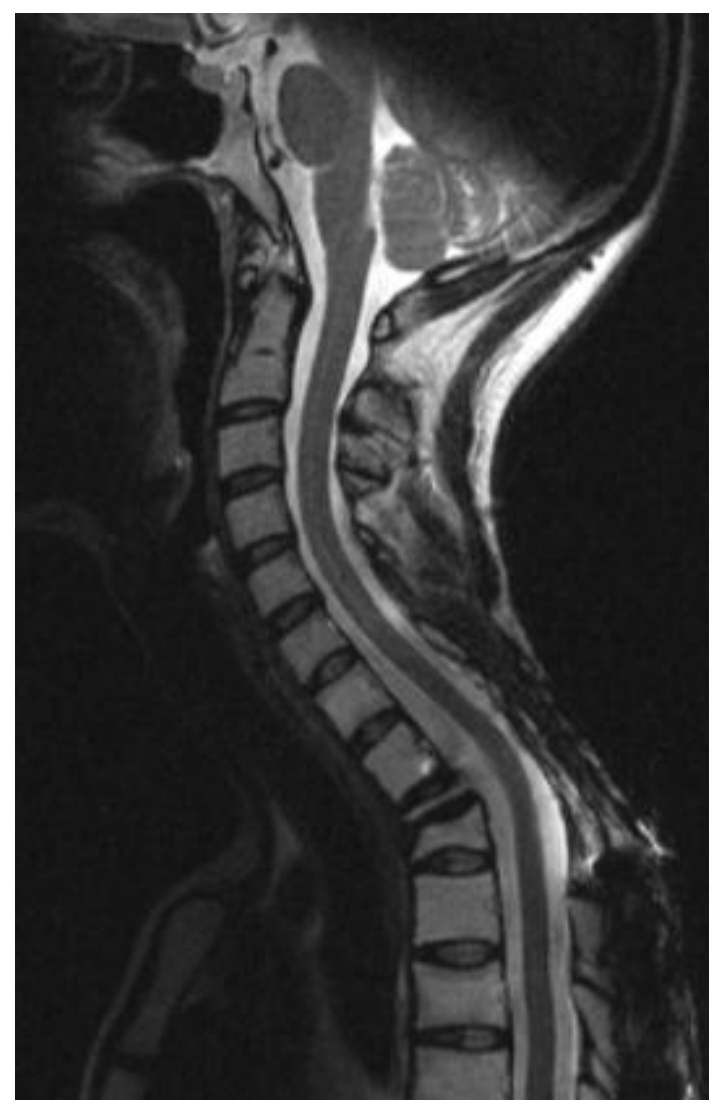

Fig. 5 

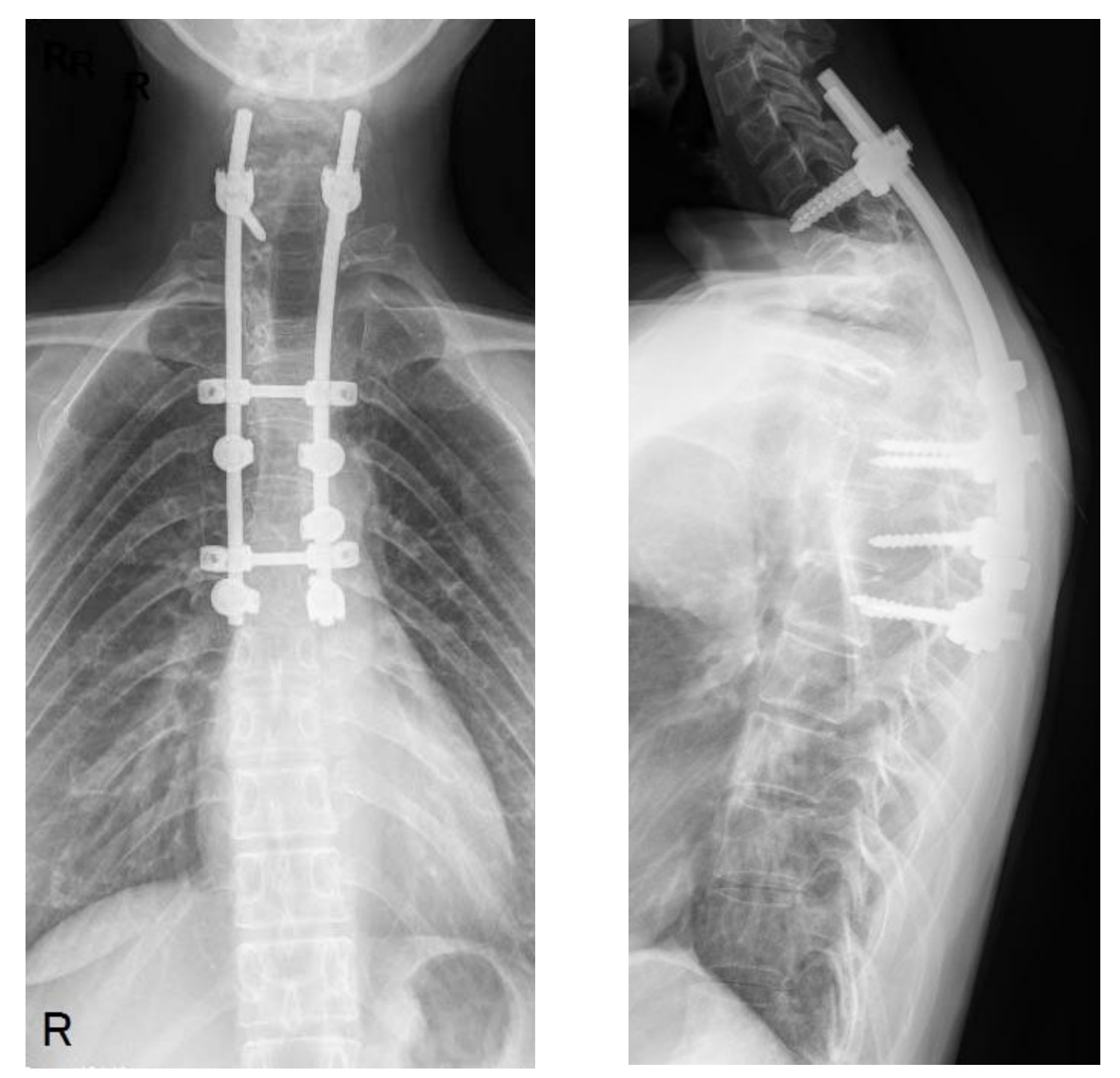

Fig. 6 